Abstract P154 Table 1 Characteristics and readmission details of patients who were reviewed by the COPD specialist nurse and completed the discharge bundle

\begin{tabular}{lll}
\hline & $\begin{array}{l}\text { Discharge Bundle } \\
(\mathrm{N}=103)\end{array}$ & $\begin{array}{l}\text { No Discharge Bundle } \\
(\mathrm{N}=53)\end{array}$ \\
\hline Area (Surrey/Hants/Berks\%) & $59 / 31 / 10$ & $53 / 30 / 17$ \\
Age in years (mean, SD) & $75(10)$ & $76(10)$ \\
Sex (male/female\%) & $45 / 55$ & $49 / 51$ \\
$>1$ admission in previous year (\%) & 27 & 28 \\
Length of stay in days (median, range) & $5(1-71)$ & $4(1-26)$ \\
Short (0/1 day) length of stay (\%) & 18 & 17 \\
30-day readmission (\%) & 17.5 & $34.0^{*}$ \\
3-month readmission (\%) & 36.9 & $52.8^{* *}$ \\
Days to readmission (mean, SD) & $33(25)$ & $28(10)$ \\
Readmissions/patient (mean, SD) & $0.55(0.95)$ & $0.68(0.83)$ \\
Hospital days/patient (mean, SD) & $9(10)$ & $9(8)$ \\
\hline * $\mathrm{P}=0.027 ;{ }^{*}$ * $\mathrm{P}=0.062$ & &
\end{tabular}

Discussion Two-thirds of patients completed a discharge bundle during the Trust's busiest quarter for COPD admission. Patients completing the discharge bundle had a significantly lower rate of 30-day readmission.

\section{P155 COMPLIANCE WITH GUIDELINES FOR THE MANAGEMENT OF THEOPHYLLINE IN PATIENTS WITH ACUTE EXACERBATIONS OF COPD}

M Ullah, D Anshur, S Lugg, S Gompertz. Queen ElizabethHospitalBirmingham, University Hospitals Birmingham NHS Foundation Trust, Birmingham, UK

\subsection{6/thoraxjnl-2014-206260.284}

Introduction Theophylline therapy has a role in COPD patients who fail to respond adequately to inhaled bronchodilators and show symptomatic benefit from a trial of the drug. Treatment is complicated by drug interactions and its narrow therapeutic range $(10-20 \mathrm{mg} / \mathrm{L})$. High serum levels increase the risk of toxicity, demonstrating numerous symptoms such as nausea, vomiting, headaches, dyspepsia, insomnia and behavioural disturbances. Serious adverse effects such as cardiac arrhythmias and epileptic seizures tend to occur at serum levels above this reference range. NICE guidelines for COPD state that a theophylline level should be measured on admission in patients admitted for acute exacerbation of COPD (AE-COPD). ${ }^{1}$ The aim of this study was to audit compliance with these guidelines.

Methods Patients with a diagnosis of AE-COPD were retrospectively analysed over a 6-month period (June-December 2013) at a university hospital. Those who were prescribed theophylline within $24 \mathrm{~h}$ of admission were included in the study. Further information was gathered including theophylline level, date of request, and subsequent dose adjustment. Paper and computerised medical and prescribing records were reviewed using a set pro-forma.

Results Of a total of 54 patients in the study, 23 patients (43\%) had theophylline levels checked during their hospital admission. Only 5 (9\%) patients had theophylline levels within $24 \mathrm{~h}$ of admission, with the mean number of days from admission to assessment being $4.69(\mathrm{SD}+5.29)$. Of those patients, 13 patients $(56.5 \%)$ had a level within subtherapeutic range $(<10 \mathrm{mg} / \mathrm{L})$, and 8 patients (61\%) receiving subsequent dose adjustment. There were no patients found to have a theophylline level above therapeutic range $(>20 \mathrm{mg} / \mathrm{l})$.

Conclusion Improvement is needed in compliance with guidelines for the theophylline monitoring in patients with AE-COPD, as more than half of patients did not have levels checked during their hospital admission. Furthermore, dose adjustments were made in only 2 of 3 patients. Changes can be implemented through education to junior doctors, implementation of electronic prescribing alerts, and adding this to our MDT COPD bundle checklist. Further prospective audit cycle will be performed to assess improvements.

\section{REFERENCE}

1 NICE Guidelines [CG101]2010

\section{P156 CAN SPECIALIST NURSES PREDICT WHICH PATIENTS WILL READMIT FOLLOWING DELIVERY OF A COPD CARE BUNDLE?}

${ }^{1} \mathrm{~L}$ Sewell, ${ }^{1} \mathrm{C}$ Mitchell-Issitt, ${ }^{1} \mathrm{~K}$ Barley, ${ }^{1} \mathrm{C}$ Chebbout, ${ }^{1} \mathrm{~S}$ Msimanga, ${ }^{1} \mathrm{~L}$ Clinch, ${ }^{2} \mathrm{~S}$ Boyce, ${ }^{1}$ MCS Steiner, ${ }^{2}$ SJ Singh. ${ }^{1}$ Centre for Exercise and Rehabilitation Science, Glenfield Hospital, University Hospitals of Leicester NHS Trust, Leicester, Leicester, UK; ${ }^{2}$ East Midlands CLAHRC, Glenfield Hospital, University Hospitals of Leicester NHS Trust, Leicester, UK

\subsection{6/thoraxjnl-2014-206260.285}

Introduction Adequate follow up is a key element of COPD care bundles (CB). COPD nurse specialists responsible for completing follow up consultations may be able to utilise clinical judgment and measures of health status to predict which patients are at greater risk of readmission.

Objective We explored whether COPD nurse specialists working in the REspiratory Discharge Service (REDS), who delivered the $\mathrm{CB}$, could predict whether patients would readmit within 15 days post discharge. We also explored levels of health and psychological status for those patients who the REDS team thought were and were not at risk of readmission.

Methods This was a retrospective audit of patients who received a COPD discharge CB from April 2013 to March 2014. Readmission likelihood was recorded by the REDS team after completion of a 2 day post-discharge phone consultation. Patients also completed the COPD Assessment Test (CAT), MRC breathlessness scale and the Hospital Anxiety and Depression Scale (HADS). Mean between-group differences for the 'will admit' and 'will not admit' groups were analysed using independent t-tests.

Results Readmission risk was recorded for 1003 patients who received the $\mathrm{CB}$ prior to discharge. A total of 100 patients of these 1003 readmitted (readmission rate of 9.7\%). The REDS team correctly predicted that 39 of these 100 patients would be readmitted. There were statistically significant between-group differences for MRC, CAT and HADS scores (see table): Patients placed in the 'will readmit' group had significantly worse CAT, HADS anxiety and depression scores compared those placed in the will not readmit group.

Conclusions COPD nurse specialists were unable to correctly predict the majority of readmissions. Patients deemed at risk of readmision had worse levels of psychological and health status than those who were not thought to be at risk of readmission.

\begin{tabular}{llll} 
Abstract P156 Table 1 & & \\
\hline & $\begin{array}{l}\text { REDs } \\
\text { " Will readmit" }\end{array}$ & $\begin{array}{l}\text { REDs } \\
\text { "Will not readmit" }\end{array}$ & p value \\
\hline MRC score & $4.28(0.68)$ & $3.75(0.90)$ & $<0.0001$ \\
CAT score & $25.25(6.97)$ & $22.91(7.55)$ & 0.012 \\
HADS anxiety & $7.97(4.95)$ & $5.86(4.23)$ & 0.001 \\
HADS depression & $7.94(4.14)$ & $5.27(3.40)$ & $<0.0001$ \\
\hline
\end{tabular}


This suggests other factors must be important in predicting COPD readmissions.

\section{P157 CANCER PATIENTS WITH SEVERE COMMUNITY ACQUIRED PNEUMONIA HAVE POORER OUTCOMES DUE TO INCREASED ILLNESS SEVERITY AND SEPTIC SHOCK AT ADMISSION TO INTENSIVE CARE}

${ }^{1} \mathrm{RJ}$ José, ${ }^{2} \mathrm{AO}$ Mohammad, ${ }^{3} \mathrm{JP}$ Goldring, ${ }^{1} \mathrm{RC}$ Chambers, ${ }^{1} \mathrm{JS}$ Brown, ${ }^{4} \mathrm{~B}$ Agarwal. ${ }^{1}$ Centre for Inflammation and Tissue Repair, Division of Medicine, University College London, London, UK; ${ }^{2}$ Department of Thoracic Medicine, Minia University, Elminia, Egypt; ${ }^{3}$ Department of Thoracic Medicine, Royal Free Hospital, London, UK; ${ }^{4}$ Department of Intensive Care Medicine, Royal Free Hospital, London, UK

\subsection{6/thoraxjnl-2014-206260.286}

Introduction Patients with community acquired pneumonia (CAP) and an underlying diagnosis of cancer have worse outcomes. However, the characteristics of cancer patients with severe CAP admitted to intensive care units are not well defined. Methods An observational study of patients admitted to a University hospital ICU with a primary diagnosis of CAP between January 2006 and October 2011.

Results 96 patients met our inclusion criteria for a diagnosis of severe CAP. 19 (19.8\%) had cancer at the time of admission to ICU (57.9\% with haematological malignancy and $42.1 \%$ with solid organ cancer). There were no statistically significant differences in age, gender or co-morbidities between those with and those without cancer. Patients with cancer had significantly higher median [IQR] APACHE II (25 [20-19] vs 20 [16-24]; p = 0.009), SAPS (51 [42-62] vs 42 [34-53]; $\mathrm{p}=0.039)$ and SOFA (12 [1013] vs 9 [4-12]; $\mathrm{p}=0.018$ ) scores and a longer median [IQR] time interval between hospital and ICU admission (2 [1-5] vs 1 $[0-3]$ days; $p=0.049)$. There were no statistically significant differences in the proportion of patients receiving mechanical ventilation or renal support and no differences in the duration of mechanical ventilation or duration of ICU or hospital stay. Patients with cancer included a significantly greater proportion of patients receiving vasopressors $(89.5 \%$ vs $63.6 \%, \mathrm{p}=0.030)$ and a markedly increased ICU $(68.4 \%$ vs $31.2 \%, \mathrm{p}=0.004)$ and hospital mortality $(78.9 \%$ vs $33.8 \%, p=0.001)$. There were no significant differences in leukocyte counts, CRP, clotting (PT, APTT and INR), renal function (urea and creatinine) or liver function (AST and ALT). There were no significant differences in heart rate, temperature, systolic blood pressure or oxygenation index. However, patients with cancer had significantly lower median diastolic blood pressure $(40 \mathrm{mmHg}$ vs $50 \mathrm{mmHg}, \mathrm{p}=0.026)$.

Conclusion Cancer patients with severe CAP continue to have an increased risk of death that appears to be related to increased illness severity at the time of ICU admission associated with septic shock. A delay in recognising the need for intensive care support in cancer patients with severe CAP may possibly explain the increased illness severity at the time of ICU admission.

\section{P158 EVALUATION OF VITAL CAPACITY CHANGES IN SPINAL INJURED PATIENTS DURING EPISODE OF SEPSIS}

M Nasher, AC Pocock, T Ward, T Bongers. Southport and Ormskirk Hospital NHS Trust, Southport, UK

10.1136/thoraxjnl-2014-206260.287

Introduction Respiratory complications have been suggested as cause of death in approximately $60 \%$ of spinal cord injured patients requiring ventilation after spinal cord injury. ${ }^{1}$ The vast

\begin{tabular}{|c|c|c|c|c|}
\hline Level & ASIA & Baseline VC & VC when unwell & Change in VC $(\%)$ \\
\hline C4 & A & 1200 & 600 & $600(50 \%)$ \\
\hline C4 & A & 2200 & 500 & $1700(77 \%)$ \\
\hline C4 & c & 2500 & 650 & 1850 (74\%) \\
\hline C4 & A & 2900 & 1500 & $1400(48 \%)$ \\
\hline C4 & c & 1630 & 980 & $650(40 \%)$ \\
\hline C4 & A & 3000 & 2930 & $70(2.3 \%)$ \\
\hline C4 & A & 1200 & 1000 & $200(16 \%)$ \\
\hline C4 & A & 3000 & 1590 & $1410(47 \%)$ \\
\hline C4 & A & 2550 & 1750 & $800(31 \%)$ \\
\hline C6 & B & 1800 & 650 & 1150 (63\%) \\
\hline C6 & B & 3400 & 800 & $2600(76 \%)$ \\
\hline C6 & B & 3570 & 2650 & $890(25 \%)$ \\
\hline T4 & A & 4000 & 3480 & $520(13 \%)$ \\
\hline T8 & A & 4000 & 1680 & $2320(58 \%)$ \\
\hline T8 & c & 3250 & 1920 & $1330(41 \%)$ \\
\hline T9 & D & 1400 & 800 & $600(43 \%)$ \\
\hline
\end{tabular}

majority of these respiratory complications are due to infections i.e. pneumonias. It has been postulated that infections trigger a general inflammatory response which directly affects respiratory muscle strength and worsens respiratory function, which can cause respiratory failure. ${ }^{2}$ All patients with a high spinal injury (> T1) or respiratory impairment have their vital capacity (VC) measured routinely at least once daily. We designed a project to assess if significant forced vital capacity (FVC) changes occur in spinal injury patients during an episode of sepsis.

Methods In this retrospective review we collected data from all our spinal injury patients with an episode of sepsis (pneumonia or urinary) between March 2010 and February 2013.

Results A total of 16 episodes were recorded in 14 patients (2 female, 12 male) with an average age of 61.8. Level of spinal cord injury varied from C4-T9 and the majority had ASIA (American Spinal Injury Association) grade A. Of all 16 episodes of sepsis, $6(37.5 \%)$ were diagnosed as pneumonia. $10(62.5 \%)$ were of urinary tract origin with positive urine culture. Blood cultures were positive in 4 cases, negative in 11 and not available in 1 . FVC ranged from $4000 \mathrm{ml}$ to $1200 \mathrm{ml}$. VC changes were more profound with respiratory infection as we observed an average FVC change of $1450 \mathrm{ml}(50-77 \%)$ for the diagnosis of pneumonia and $862 \mathrm{ml}(2.3-58 \%)$ for urinary tract infection Conclusions Systemic infection causes significant changes in vital capacity suggesting direct effect of the inflammatory process on diaphragmatic and respiratory muscle function. These VC changes are more profound with respiratory infection and in our study varied from 50\%-77\% reduction from the baseline. Reduction in VC is an important sign of clinical deterioration and should be routinely measured in any patient with spinal cord injury to prevent respiratory compromise and respiratory failure.

\section{REFERENCES}

1 Watt J et al. Spinal Cord.2011:49:404-10

2 Boczkowski J. Am J Respir Crit Care Med.2004;169:662-663

\section{P159 WEANING AND LONG TERM VENTILATION OUTCOMES IN SPINAL INJURY PATIENTS AFTER REFERRAL TO A REGIONAL SPINAL INJURY CENTRE}

AC Pocock, M Nasher, T Ward, T Bongers. Southport and Ormskirk Hospital NHS Trust, Southport, UK

10.1136/thoraxjnl-2014-206260.288 